\title{
Impact of the inflow moisture on the evolution of a warm conveyor belt
}

\author{
Andreas Schäfler ${ }^{\mathrm{a} \star}$ and Florian Harnisch ${ }^{\mathrm{a}, \mathrm{b}}$ \\ ${ }^{a}$ Deutsches Zentrum für Luft- und Raumfahrt, Institut für Physik der Atmosphäre, Oberpfaffenhofen, Germany \\ ${ }^{\mathrm{b}}$ Hans-Ertel-Zentrum für Wetterforschung, Bereich Datenassimilation, Meteorologisches Institut, Ludwig-Maximilians-Universität, \\ München, Germany \\ ${ }^{\star}$ Correspondence to: A. Schäfler, Institut für Physik der Atmosphäre, DLR Oberpfaffenhofen, D-82230 Wessling, Germany. \\ E-mail: andreas.schaefler@dlr.de
}

\begin{abstract}
This case study of a warm conveyor belt (WCB) event that was probed on a research flight during the THORPEX (The Observing-System Research and Predictability Experiment) Pacific Asian Regional Campaign (T-PARC) field experiment in 2008, investigates the sensitivity of the forecast of the WCB, the associated cyclone and the downstream waveguide to the moisture content in the inflow region of the WCB. By assimilating water vapour profiles of a differential absorption lidar (DIAL) into the European Centre for Medium Range Weather Forecasts (ECMWF) Integrated Forecasting System (IFS), the inflow moisture in the analysis fields is adjusted and humidity is reduced in a broad region around the flight track. The initial reduction of moisture in the WCB inflow affects the latent heat release along the WCB, as well as the potential vorticity (PV) production at lower levels. This change led to a substantially lower outflow height of the forecasted WCB. Further, the height of the tropopause was reduced up to $20 \mathrm{hPa}$, which caused a change in the jet stream wind speeds of up to $15 \%$ downstream. Although the impact on the developing surface cyclone was small, improvements of the PV structure as well as of the kinetic energy could be identified.
\end{abstract}

Key Words: differential absorption lidar; data assimilation; water vapour; T-PARC

Received 29 July 2013; Revised 9 January 2014; Accepted 3 March 2014; Published online in Wiley Online Library 30 April 2014

\section{Introduction}

Atmospheric moisture and its transport play an important role at different scales of motion in atmospheric dynamics. It is the property of water vapour to release energy during cloud condensation that affects the evolution of convection. The release of latent heat provides a major heat source to the general circulation, especially in the tropics. A majority of the condensational processes in extratropical cyclones are controlled by saturated air ascending in a coherent airstream: the so-called warm conveyor belt (WCB). A WCB denotes an ascending airflow carrying warm and moist air from the southern midlatitude boundary layer to the northern midlatitude upper troposphere in 1-2 days (Browning et al., 1973; Carlson, 1980; Wernli and Davies, 1997). During the ascent (typically $400-600 \mathrm{hPa}$ in $48 \mathrm{~h}$ ) the air cools adiabatically until saturation is reached and cloud formation starts. Eckhardt et al. (2004) show that the intense diabatic latent-heat release associated with condensation causes an increase of potential temperature (up to $20 \mathrm{~K}$ ) in the ascending airstream, representing a cross-isentropic transport.

Diabatic processes in WCBs are vitally important because they strongly influence the life cycle of developing individual extratropical cyclones. Condensation processes in the coherently ascending airstream produce a positive potential vorticity (PV) anomaly in the lower troposphere below the level of maximum latent heating (Wernli and Davies, 1997). This positive diabatic PV modification can intensify the subsequent life cycle of a cyclone (e.g. Kuo etal., 1991; Davis et al., 1993; Rossa et al., 2000). Above the level of maximum latent heating, PV is reduced by diabatic processes leading to negative PV anomalies in the upper tropospheric WCB outflow region (Wernli, 1997; Pomroy and Thorpe, 2000; Grams et al., 2011). This modification of upper tropospheric PV, usually occurring at the level of the midlatitude jet stream, can significantly affect the wavelength and amplitude of the downstream Rossby wave development by modifying the upper-level ridge (Massacand et al., 2001; Knippertz and Martin, 2005).

The magnitude of diabatic processes depends on the low-level moisture content that is available in the inflow region, i.e. the area where moist air masses converge before they coherently ascend in the WCB. Analysis fields of current numerical weather prediction (NWP) models still exhibit large humidity errors, especially at lower levels (Schäfler et al., 2010, 2011). Hence, insufficiencies in the representation of the moisture content, i.e., the WCB inflow region, as diagnosed, e.g., by Schäfler et al. (2011), can be expected to influence the large-scale dynamics and represent a possible source of forecast errors downstream of the WCB. 
In this study we want to demonstrate that a correction of the initial moisture errors in the analysis can have a significant effect on the forecast. The importance of the correct initial moisture field is investigated in a case study of a WCB that was probed with aircraft observations during The Observing-System Research and Predictability Experiment (THORPEX) Pacific Asian Regional Campaign (T-PARC) that took place during August-October 2008 over the western North Pacific. The evolution of the WCB in the European Centre for Medium Range Weather Forecasts (ECMWF) global model forecast is examined in detail. The sensitivity of the forecast to the initial moisture is investigated by analysing the forecasts of a WCB from two model runs, which were initialized from: (i) an analysis using all operational observations; and (ii) an analysis that additionally assimilates high-resolution lidar water vapour observations. It is shown that the improved representation of the initial humidity field in the inflow region of the WCB by assimilating lidar data, leads to a different evolution of the WCB, which subsequently leads to an improved NWP forecast.

Section 2 introduces the assimilated observations, the performed NWP model experiments and the trajectory computation that provides an evaluation tool for WCBs. A synoptic overview is presented in section 3, including a description of the observed water vapour structure and the identification of the WCB. The impact of a modified initial moisture field on the analysis and forecast is shown in section 4 and results are discussed and summarized in section 5 .

\section{Data and methods}

\subsection{The DIAL water vapour observations}

In this study observations of the Water Vapour Lidar Experiment in Space (WALES) airborne demonstrator instrument were used. WALES is an airborne four-wavelength DIAL that was developed recently at the Deutsches Zentrum für Luft- und Raumfahrt (DLR) (Wirth et al., 2009). Observing water vapour with a DIAL has proven to be a reliable method to remotely observe water vapour concentrations on board research aircraft (e.g. Kiemle et al., 2008; Schäfler et al., 2010). With an error that is evaluated to be less than 5-7\% (Kiemle et al., 2007; Bhawar et al., 2011), the water vapour concentration can be deduced by comparing returned signals of two spectrally narrow laser pulses that were emitted to the atmosphere. The light pulses become extinct by scattering and absorption on air molecules and aerosol particles during their passage through the atmosphere. The detected signal depends on the backscattering capability of the atmospheric constituents. If the selected wavelengths feature the same scattering and extinction properties with respect to aerosol and molecules, so that the detected signal difference is solely due to water vapour absorption, the mean trace-gas concentration of the illuminated volume can be determined. The wavelengths of the laser pulse are often selected in the near infrared spectral region that is characterized by narrow water vapour absorption lines. One of the laser pulses is positioned on a water vapour absorption line and the other at a non-absorbing wavelength. The DLR WALES instrument offers the possibility to measure profiles over the whole range of water vapour concentrations, often varying by up to four orders of magnitude between the ground and the flight level in the upper troposphere/lower stratosphere region. The observation of water vapour up to the tropopause succeeds by comparing the returned signal of three wavelengths that are sensitive at different water vapour concentrations, i.e., different altitudes, to the reference wavelength at a non-absorbing wavelength. The four wavelengths are located in the water vapour absorption band at $935 \mathrm{~nm}$ (Wirth et al., 2009).

The nadir-pointing WALES instrument was installed on board the DLR Falcon 20 aircraft during T-PARC. The campaign goals were to enhance the understanding of the dynamics of tropical cyclones (TCs) and to improve their forecasts.
About 3900 water vapour profiles could be sampled during 25 research flights over the western North Pacific Ocean. The resolution of the presented profiles is $\sim 30 \mathrm{~s}(\sim 6 \mathrm{~km})$ in the horizontal and $300 \mathrm{~m}$ in the vertical. The observed DIAL water vapour profiles are characterized by a high spatial resolution and small observation errors, which can expected to be less than $7 \%$. In addition, the Falcon aircraft was equipped with a Doppler wind lidar (DWL) and a dropsonde system. These observations were examined in different studies (e.g. Harnisch and Weissmann, 2010; Weissmann et al., 2012) and are not considered here.

\subsection{The NWP model experiments}

Two different NWP experiments have been performed with the ECMWF Integrated Forecasting System (IFS). The experiments have a horizontal resolution of T799 wavenumber truncation $(\sim 25 \mathrm{~km})$ and 91 vertical levels. Two 10-day forecast experiments were initialized at 0000 UTC on 19 September 2008 based on different analyses as initial conditions. Except for the initial conditions, these two forecasts are identical. The first experiment, CTRL, is initialized from the operational analysis and differs to the operational ECMWF forecast only by using an updated model version (model cycle 36r1). The second experiment, EXP_DIAL, is started from an analysis that was computed with the operational 4D-Var data assimilation system (e.g. Rabier et al., 2000; Bauer et al., 2010) assimilating the DIAL water vapour observations on top of all operational observations.

The DIAL system measures the number concentration of water molecules that can be converted to absolute humidity. With an effective vertical resolution of the instrument of about $300 \mathrm{~m}$, vertically resolved values of precipitable water content (PWC) can be derived for layers of $300 \mathrm{~m}$ depth. The sum of these vertical layers of PWC over the whole atmosphere yields the total water column. For vertically resolved PWC, an observation operator, which was originally developed for data from the solar backscattering UV satellite instrument, has been applied. In the horizontal, five DIAL profiles have been averaged producing a superobservation with $\sim 25-30 \mathrm{~km}$ horizontal resolution, which is similar to the model resolution. An observation error standard deviation of $15 \%$ has been assigned in the data assimilation. For more details on the assimilation of the DIAL water vapour measurements in the ECMWF 4D-Var data assimilation system refer to Harnisch et al. (2011).

It should be noted that the EXP_DIAL experiment is consistent with the AV_DIAL experiment in Harnisch et al. (2011). Both experiments in this study, CTRL and EXP_DIAL, do not assimilate dropsonde observations of the DLR Falcon in order to avoid any possible interaction between the DIAL water vapour profiles and the dropsonde data.

\subsection{Trajectory computation}

The Lagrangian analysis tool (LAGRANTO, Wernli and Davies, 1997) is employed, which allows calculating three-dimensional kinematic trajectories and selecting trajectories using objective criteria, e.g. WCB trajectories based on a pressure change along trajectories. The LAGRANTO tool additionally allows tracing meaningful meteorological variables, e.g. temperature, potential temperature, specific humidity and potential vorticity. For further details on the trajectory computation refer to Schäfler et al. (2011). In this study two different types of calculations are presented that differ by the starting time, starting location and selection criterion.

The first method has the purpose to identify ascending air masses captured by the DIAL measurements. Air-parcel trajectories are calculated from every observation point on the lidar cross-section at the respective observation time using wind fields of the ECMWF operational analysis. An 8-day combined trajectory is composed of a backward part that represents the transport in the 2 days before and a forward part that depicts the 6 days after the observations. These parcel pathways are then 

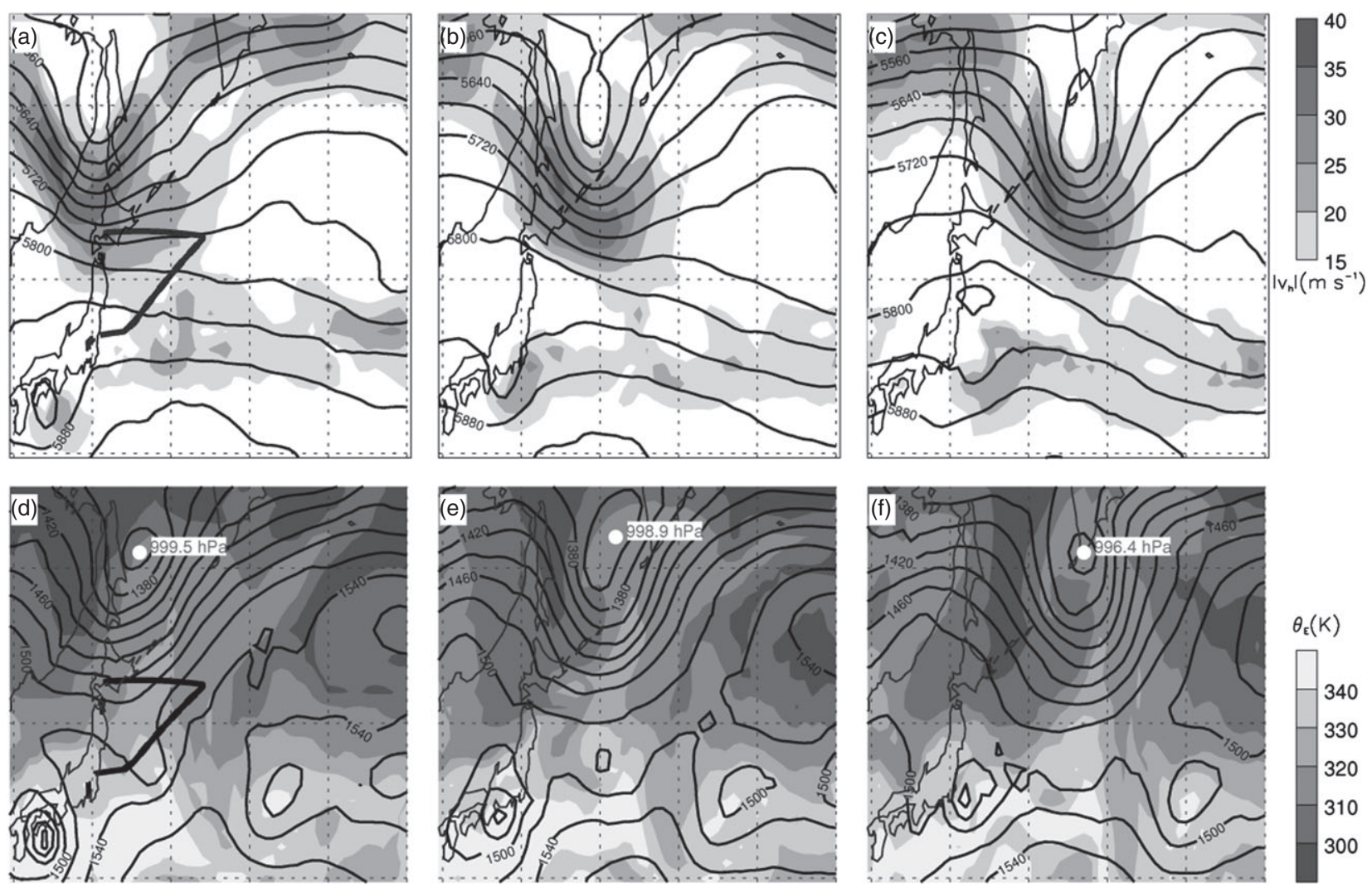

Figure 1. ECMWF analysis of $(\mathrm{a}-\mathrm{c})$ geopotential height $\left(\mathrm{m}\right.$, black lines) and horizontal wind speed $\left(\mathrm{m} \mathrm{s}^{-1}\right.$, shaded areas) at 500 hPa ( $\left.-\mathrm{f}\right)$ geopotential height (m, black lines) and equivalent potential temperature (K, shaded) at $850 \mathrm{hPa}$ valid at (a,d) 0000 UTC on 19 September (b,e) $1200 \mathrm{UTC}$ on 19 September and (c,f) 0000 UTC on 20 September 2008. The thick black line in (a) and (d) shows the location of the lidar measurements. White dots with labels in panels (d-f) show location and value of the minimum seal-level pressure.

analysed for the maximum pressure decrease (maximum ascent) $\Delta p_{\max }$ in $48 \mathrm{~h}$ at any time during the evaluated 8-day period. To illustrate the vertical and horizontal distribution of the ascending air masses, the maximum pressure decrease in $48 \mathrm{~h}$ exceeding $400 \mathrm{hPa}$ is visualized along the cross-section.

The second method aims at investigating the impact of the data assimilation of water vapour data on the forecast of the WCB. The calculation consists of forward trajectories that are computed at every model grid point in a domain covering the inflow region of the WCB. Trajectories are initialized from every grid point between the sea surface and $700 \mathrm{hPa}$ in an area from 142 to $155^{\circ} \mathrm{E}$ and 39 to $45^{\circ} \mathrm{N}$. The calculation is performed with model fields of EXP_DIAL and CTRL forecast experiments starting at 0000 UTC on 19 September 2008 to compare the representation of the WCB in both forecast experiments. The WCBs are typically identified with a criterion that requires a $600 \mathrm{hPa}$ pressure decrease in $48 \mathrm{~h}$ (Wernli and Davies, 1997). As most of the observations ascend by more than $500 \mathrm{hPa}$ (see discussion of Figure 3 in section 3.3) and the data assimilation impacts the moisture in a broader region around the flight track (see Harnisch et al., 2011 and discussion of Figure 5 in section 4.1), we use a less restrictive threshold of $500 \mathrm{hPa}$ in $48 \mathrm{~h}$ to study the location of the WCB inflow and its position relative to the flight. In a first step, the WCB trajectories are identified in the CTRL forecast as parcels that ascend more than $500 \mathrm{hPa}$ in $48 \mathrm{~h}$. Then trajectories using the EXP_DIAL forecast wind fields are calculated from the same starting points to enable a comparison of the trajectories from the two experiments.

\section{The 19 September 2008 case}

\subsection{Synoptic overview}

The flight of the DLR Falcon aircraft on 19 September 2008 (see flight path in Figure 1(a) and (d)) started in the north of the Japanese main island Honshu at around 0110 UTC and continued eastward over the Pacific Ocean. At $\sim 154^{\circ} \mathrm{E}$ the aircraft turned southwestward and landed in Atsugi at around 0510 UTC. The DIAL water vapour observations were collected between $\sim 0145$ and 0430 UTC.

At 0000 UTC on 19 September 2008 the synoptic situation over the western North Pacific was characterized by an upperlevel trough with a distinct wind maximum at $500 \mathrm{hPa}$ that approached northern Japan (Figure 1(a)). Further downstream of the trough, a broad ridge extended over large parts of the North Pacific Ocean. The location of the tropical cyclone (TC) Sinlaku can be recognized south of Japan by the closed contour lines in the geopotential height contours at 500 and $850 \mathrm{hPa}$ (Figure 1(a) and (d)). The flight was located between the TC Sinlaku and a developing extratropical cyclone to the north. On the leading edge of the midlatitude trough, warm and moist air was advected northeastward, as confirmed by the high values of equivalent potential temperature $\theta_{\mathrm{E}}$. Sharp gradients of $\theta_{\mathrm{E}}$ to the west and north of the cyclone centre indicate cold and warm fronts associated with the evolving cyclone. The flight crossed the tongue of increased $\theta_{\mathrm{E}}$ values and reached tropical air masses northeast of the TC Sinlaku at the end of the flight. Twelve hours later, at 1200 UTC on 19 September 2008, the trough at $500 \mathrm{hPa}$ propagated eastward, as shown by the geopotential height field (Figure 1(b)). Additionally, the warm and moist air moved northeastward and the frontal zone (strong $\theta_{\mathrm{E}}$ gradient; Figure 1(e)) became more deformed. Another $12 \mathrm{~h}$ later, at 0000 UTC on 20 September, a closed contour formed at $500 \mathrm{hPa}$. Over the time period of $24 \mathrm{~h}$ shown in Figure 1 the cyclone intensified, as can be seen from the decrease in geopotential height of $\sim 20 \mathrm{~m}$ at $850 \mathrm{hPa}$ and in the reduction of minimum sea-level pressure (MinSLP) by $3.1 \mathrm{hPa}$ (Figure 1(d)-(f)).

Figure 2 shows visible satellite imagery of the geostationary Multi-functional Transport Satellite (MTSAT). A few hours before the observations, at 0000 UTC on 19 September 2008, Figure 2(a) depicts the cloud system of the TC Sinlaku and its upper-level outflow indicated by the high-level clouds around 

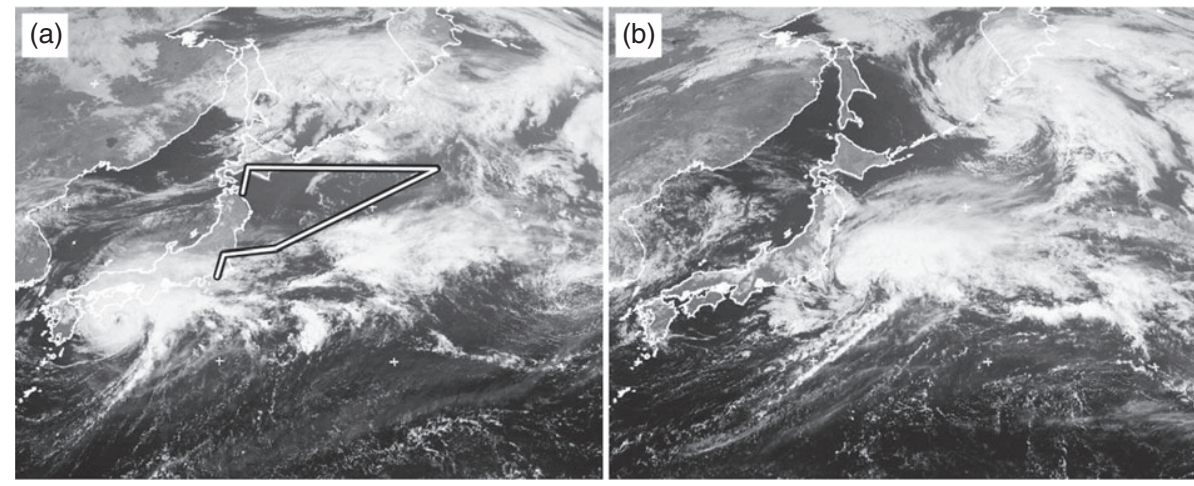

Figure 2. MTSAT satellite imagery (VIS, Channel 1) at (a) 0000 UTC on 19 September and (b) 0000 UTC on 20 September 2008 (from NERC Satellite Receiving Station, Dundee University, Scotland, http://www.sat.dundee.ac.uk). White line in (a) indicates the flight track.

(a)

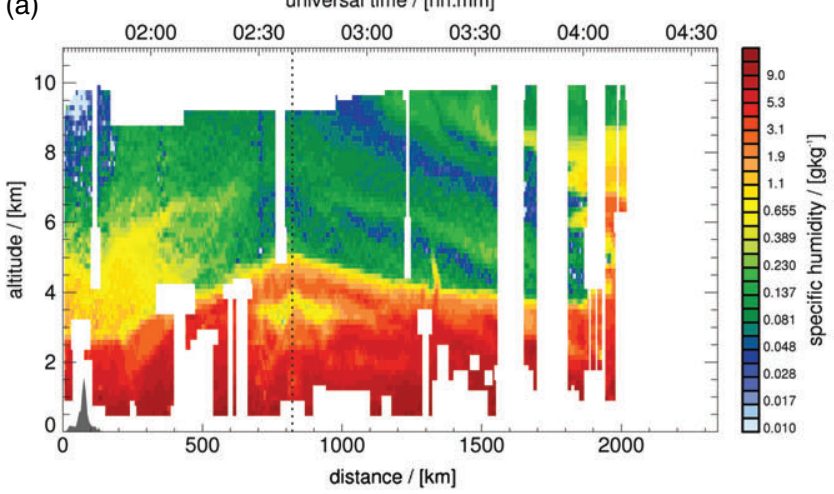

(b)

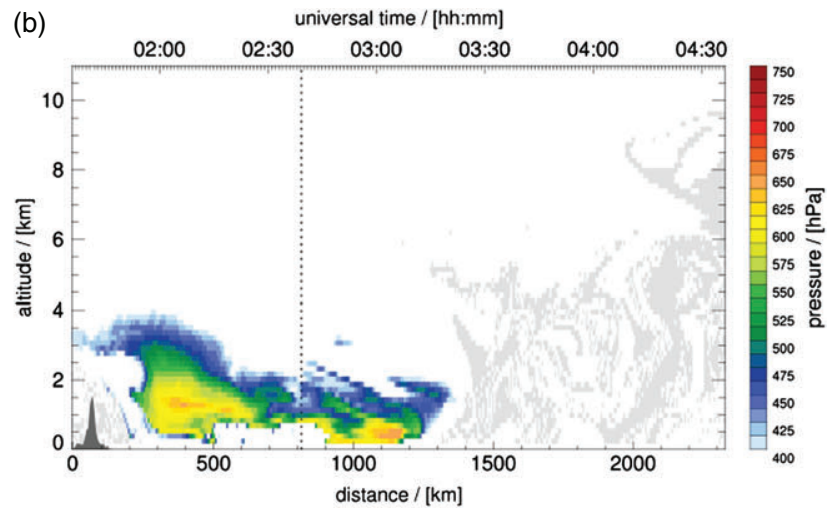

Figure 3. (a) The differential absorption lidar measurements of specific humidity $\left(\mathrm{g} \mathrm{kg}^{-1}\right.$, in logarithmic scale) on 19 September 2008. (b) Maximum decrease of pressure $\Delta p_{\max }(\mathrm{hPa})$ in $48 \mathrm{~h}$ along trajectories. Only locations of trajectories with an ascent greater than $400 \mathrm{hPa}$ in $48 \mathrm{~h}$ are considered. Light grey areas indicate convective upward transport close to tropical cyclone Sinlaku. Dark grey area (at a distance $\sim 50 \mathrm{~km}$ ) shows the topography interpolated from GLOBE-DEM (Hastings et al., 1999). Dotted line in (a) and (b) indicates the turn of the aircraft at $154^{\circ} \mathrm{E}$ (see Figure 1).

the storm centre (see also Figure 1(a) and (d)). Dense high-level clouds formed along the warm front of the midlatitude cyclone located west of the Kamchatka Peninsula. In the southwest of the low-pressure system, convective clouds are visible along the cold front passing the north Island of Japan (compare with location of the $\theta_{\mathrm{E}}$ gradients in Figure $1(\mathrm{~d})$ ). East of Japan, between the tropical and midlatitude cyclone, almost cloud-free conditions prevailed in the area where the flight took place some hours later. The aircraft reached convective clouds northeast of the tropical storm at the end of the flight. The TC Sinlaku moved northeastward during the next $24 \mathrm{~h}$ (Figure 2 (b)). The midlatitude cyclone intensified and propagated eastward. The centre of the occluded frontal system is located south of Kamchatka (compare with Figure 1(c) and (f)).

\subsection{The DIAL water vapour observations}

Figure 3 illustrates the DIAL water vapour measurements that were observed between 0135 and 0440 UTC, with cloud-free conditions in the area between the midlatitude and tropical cyclone before 0340 UTC. Water vapour observations were not possible in the last part of the flight due to upper-level clouds related to deep convection northeast of the TC Sinlaku, which attenuate the DIAL signal. The appearing symmetry in the moisture distribution results from the turning of the aircraft near $154^{\circ} \mathrm{E}$, which was reached at about $820 \mathrm{~km}$ distance (see dotted line in Figure 3(a) and (b)).

A thick ground-based moist layer characterizes large parts of the flight. The upper edge of this layer shows a strong vertical humidity gradient that is less sharp in the first part of the flight, where higher values $\left(\sim 1 \mathrm{~g} \mathrm{~kg}^{-1}\right)$ are observed up to about $6 \mathrm{~km}$ altitude before $\sim 0200$ UTC. On the southwesterly oriented part of the flight the vertical humidity gradient at $\sim 4 \mathrm{~km}$ altitude is very strong and the specific humidity decreases from $\sim 3$ to $\sim 0.1 \mathrm{~g} \mathrm{~kg}^{-1}$ in a vertical layer of $\sim 1 \mathrm{~km}$. The thickness of the moist layer decreases on the southwestward oriented part of the flight from $4.5 \mathrm{~km}$ to about $3.5 \mathrm{~km}$. Low- and mid-level clouds appear at a distance of $\sim 500 \mathrm{~km}$ in an area of enhanced $\theta_{\mathrm{E}}$ values (Figure 1(d)) that suggest reduced stability. At the end of the flight and close to the convective region at $\sim 0400$ UTC the observations indicate high humidity values in the upper troposphere (up to $1 \mathrm{~g} \mathrm{~kg}^{-1}$ at $8 \mathrm{~km}$ altitude).

\subsection{Characterization of the WCB}

Figure 3(b) shows the maximum change in pressure $\left(\Delta p_{\max }\right)$ over a $48 \mathrm{~h}$ interval along the trajectories started at each observation point for the case that $\Delta p_{\max }$ exceeds $400 \mathrm{hPa} . \Delta p_{\max }$ was calculated along an 8-day trajectory running 2 days backward and 6 days forward from the observation time. A coherent layer with a maximum depth of $\sim 4 \mathrm{~km}$ at 0200 UTC indicates an observed air mass that is part of a WCB and possesses maximum ascent rates of up to $650 \mathrm{hPa}$. Two maxima in the magnitude of the WCB ascent are located before and after the turning point. An analysis of the time the observed WCB parcels start their ascent relative to the observation time (not shown) reveals that the observed WCB air mass rises immediately after the observation. This means that the inflow region of a WCB in advance of the strong ascent was detected. During the second part of the flight (after 0320 UTC) the trajectories showed less coherence and strong convectively driven uplift related to the TC Sinlaku (not shown). These parcels (grey shading in Figure 3) are neglected in the following as they do not belong to the WCB airmass.

Figure 4 shows the transport pathways of the observed WCB air mass starting 2 days before (Figure 4(a)) and ending 6 days after the observations (Figure 4(b)), as well as the evolution of pressure, specific humidity and potential temperature along the respective trajectories (Figure 4(c)-(e)). The combined $192 \mathrm{~h}$ 

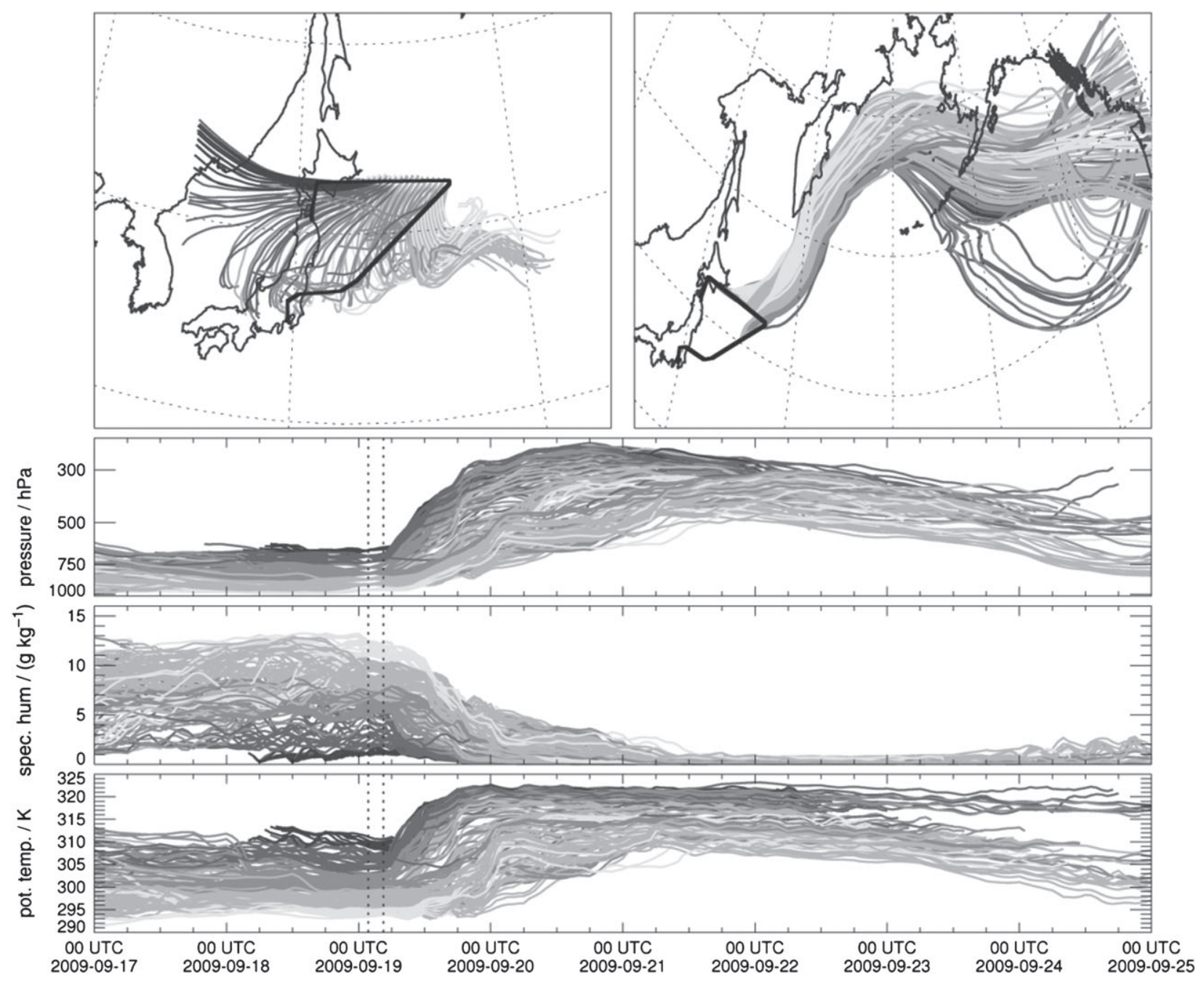

Figure 4. Trajectories of warm conveyor belt parcels ascending more than $400 \mathrm{hPa}$ in $48 \mathrm{~h}$. Trajectories are shaded according to the pressure at the time of the observations: (a) before and (b) after the observations. Black line in (a) and (b) indicates the flight track. Temporal development of (c) pressure, (d) specific humidity and (e) potential temperature. The dashed vertical lines in (c), (d) and (e) indicate the beginning and end of the lidar observations.

(8-day) trajectories start at 0000 UTC on 17 September and end at 0000 UTC on 25 September 2008. Dark grey colours indicate trajectories of observations at higher altitudes $(600 \mathrm{hPa})$, whereas brighter colours belong to the trajectories at lower levels $(1000 \mathrm{hPa})$. At the observation time the moisture content of the trajectories varies from 1 to $12 \mathrm{~g} \mathrm{~kg}^{-1}$ and the potential temperature of the trajectories ranges between 292 and $310 \mathrm{~K}$. The WCB airmass is mostly advected horizontally towards the measurement location. At high altitudes (dark grey trajectories) the air is advected from westerly directions over China possessing high potential temperatures $(\sim 310 \mathrm{~K})$. Going to lower altitudes the advection of the observed air mass veers from southwesterly to southeasterly directions at the lowest levels (light grey trajectories). Towards the sea surface the air becomes more humid.

After the observation, the WCB air mass moves coherently northeastward and passes Kamchatka to the east, before the trajectories disperse horizontally and vertically and move anticyclonically to the east (Figure 4(b)). Observed WCB trajectories rise immediately after the time the observations were taken, which confirms that the DIAL measurements were obtained in the inflow region of the WCB in advance of the strong ascent in the vicinity of the trough. The condensational processes that characterize the WCB ascent occur south and east of Kamchatka and are associated with a strong increase of potential temperature and a decrease of moisture. The most humid trajectories lose about $12 \mathrm{~g} \mathrm{~kg}^{-1}$ (Figure 4(d)) and increase their potential temperature by $\sim 20 \mathrm{~K}$ due to latent heating. The latent heat release mainly takes place in the first 2 days after the observations. Figure 4(b) also depicts that the upper part of the WCB observations (darker trajectories) ascends earlier compared with the lower ones, which leads to vertical dispersion. Additionally, the faster rising trajectories are lifted to higher altitudes and after having reached the outflow stage after $\sim 2$ days they show a stronger anticyclonic curvature with a flow that is located further south. The southern part of the westerly flow proceeds at higher altitudes $(\sim 280 \mathrm{hPa})$ and at higher potential temperatures $(\sim 320 \mathrm{~K})$ compared with the northern part $(\sim 350 \mathrm{hPa}, \sim 310 \mathrm{~K})$. The ascending parcels in the western and central part of the WCB possess the largest vertical displacement in $48 \mathrm{~h}$ (up to $\sim 650 \mathrm{hPa}$ ). Note that these parcels are the closest to the cold front and the cyclone centre. In the outflow region the strongest rising parcels are distributed in both transport pathways. The trajectories feature a slight descent on the rear side of the trough in the anticyclonic outflow and further downstream. This descent is accompanied by a decrease in potential temperature, which probably is due to radiative cooling. At the end of the 8-day period, the trajectories are embedded in an upper-level trough east of the North American west coast.

\section{Results}

\subsection{Impact on the analysis}

A comparison of the CTRL and EXP_DIAL analysis (Figure 5(a)) reveals a distinctive difference in the humidity in a broad region around the flight track, with maximum values close to $2 \mathrm{~g} \mathrm{~kg}^{-1}$. This difference indicates higher values of humidity in the CTLR analysis using the operationally available observations. The additional assimilation of DIAL humidity observations leads to an overall removal of moisture, especially in the lower troposphere 

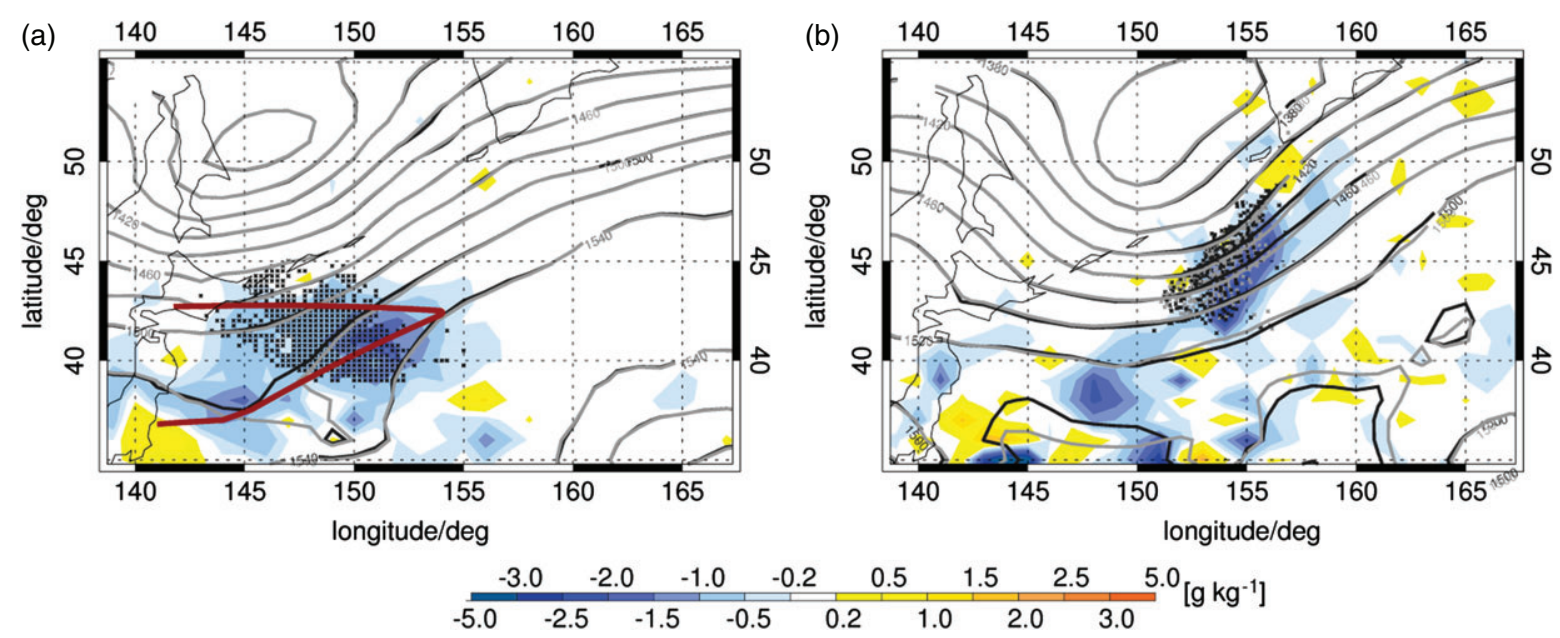

Figure 5. Absolute difference (EXP_DIAL - CTRL) of specific humidity $\left(\mathrm{g} \mathrm{kg}^{-1}\right)$ for (a) the analysis at $0000 \mathrm{UTC}$ on 19 September 2008 and (b) the $+12 \mathrm{~h}$ forecast initialized at 0000 UTC on 19 September 2008. Grey (CTRL) and black (EXP_DIAL) contour lines indicate the geopotential height (m) at 850 hPa. Positions of ascending warm conveyor belt (WCB) trajectories calculated with forecasts based on the EXP_DIAL (black dots) and CTRL (grey dots) wind fields. The WCB trajectories are parcels that are lifted from every grid point between the sea surface and $700 \mathrm{hPa}$ in an area from 142 to $155^{\circ} \mathrm{E}$ and 39 to $45^{\circ} \mathrm{N}$ by more than $500 \mathrm{hPa}$ in $48 \mathrm{~h}$. Only parcels that are located at $850 \pm 20 \mathrm{hPa}$ are indicated. Red line indicates the Falcon flight track.

(below $700 \mathrm{hPa}$ ). Verification of the analysis against independent dropsonde humidity observations has shown that the reduced humidity in the EXP_DIAL analysis improves the analysis accuracy at 0000 UTC on 19 September 2008 (see figure 5(a) in Harnisch et al., 2011).

The centre of the developing midlatitude cyclone is located north of the flight path at analysis time (Figure 5(a)). The geopotential height contour lines of CTRL and EXP_DIAL analyses are very similar and only small differences are apparent south of $40^{\circ} \mathrm{N}$, where the gradient of the geopotential height is weak. At the analysis time, the identified WCB trajectories (indicated as black dots in Figure 5(a)) are placed in a broad region around the flight track in the southern part of the leading edge of the trough at $850 \mathrm{hPa}$. The WCB inflow region also coincides with the area of maximum humidity difference. It should be noted that the trajectories presented are based on the second method described in section 2.3. As only trajectories that ascend more than $500 \mathrm{hPa}$ are considered as WCB trajectories, no WCB starting points are found close to the turning point of the aircraft where the maximum pressure decrease is lower (see Figure 3(b)). The coincidence of the humidity difference and the WCB inflow implies that a different amount of moisture is transported within the WCB of the two experiments, which suggests that the humidity change can have a direct impact on the forecast of the WCB, the evolution of the cyclone and the downstream development.

\subsection{Impact on the forecast}

After $+12 \mathrm{~h}$ forecast time, the trough and the corresponding cyclone at $850 \mathrm{hPa}$ have moved eastward (Figure 5(b)). The differences of geopotential height between CTRL and EXP_DIAL are still small. Only on the leading edge of the trough at $850 \mathrm{hPa}$ the contours differ slightly. Similarly, the area of large humidity differences is displaced northeastwards during the first $12 \mathrm{~h}$ of the forecasts. The WCB trajectories driven by EXP_DIAL (black dots) and CTRL (grey dots) forecast wind fields are both located at similar positions in the area of maximum negative humidity deviations. Note the horizontal aggregation of the WCB air parcels on the leading edge of the trough. The persistence of the difference signal during the first $12 \mathrm{~h}$ can be explained by the almost horizontal transport and constant humidity values of the trajectories at $850 \mathrm{hPa}$ (Figure 4(c)).

For a detailed investigation of the structure of the WCB, the key meteorological variables of pressure, potential temperature, specific humidity and PV are evaluated along WCB trajectories as a function of the forecast lead time for both the CTRL and EXP_DIAL forecasts (Figure 6). The mean values presented are significantly different at a $99 \%$ confidence level for almost all forecast lead times. Figure 6(a) shows the distribution of pressure for 3-hourly time steps. Both pressure distributions agree at the analysis time because all trajectories start at the same location. The mean pressure of the WCB starting points is $920 \mathrm{hPa}$ and the highest parcels start at $750 \mathrm{hPa}$. During the first $12 \mathrm{~h}$, the parcels of both forecast experiments ascend only slightly and possess similar, relatively narrow distributions. However, it appears that the parcels in the CTRL forecast are located slightly higher compared with the EXP_DIAL forecast (Figure 6(a)), which becomes more emphasized after $+12 \mathrm{~h}$ forecast time when the parcels begin to ascend and disperse vertically. After $+24 \mathrm{~h}$ the trajectories reach the mid troposphere and the mean WCB pressure of the CTRL forecast $\left(\bar{p}_{\text {CTRL }}(+24 \mathrm{~h})=435 \mathrm{hPa}\right)$ is $65 \mathrm{hPa}$ lower compared with the EXP_DIAL forecast $\left(\bar{p}_{\text {EXP_DIAL }}(+24 \mathrm{~h})=500 \mathrm{hPa}\right)$. Between +24 and $+48 \mathrm{~h}$ most WCB trajectories reach the outflow stage, with WCB trajectories of CTRL being located at higher levels $\left(\bar{p}_{\text {CTRL }}(+48 \mathrm{~h})=332 \mathrm{hPa}, \bar{p}_{\text {EXP_DIAL }}(+48 \mathrm{~h})=400 \mathrm{hPa}\right)$. Some of the trajectories in the EXP_DIAL forecast are at first lifted, but they do not pass the mid troposphere and remain at lower levels (see 10th percentile).

The WCB parcels start with comparable potential temperatures in CTRL and EXP_DiAL $\left(\bar{\theta}_{\text {CTRL,EXP_DiAL }}(+0 \mathrm{~h}) \approx 296.5 \mathrm{~K}\right)$ (Figure 6(b)). The ascent is associated with an increase of potential temperature, whereby the latent heating processes are strongest between +12 and $+24 \mathrm{~h}$ forecast lead time when the parcels are ascending to the mid troposphere. The highest mean potential temperatures are reached after $33 \mathrm{~h}\left(\bar{\theta}_{\mathrm{CTRL}}(+33 \mathrm{~h}) \approx 317.7 \mathrm{~K}\right.$, $\left.\bar{\theta}_{\text {EXP_DIAL }}(+33 \mathrm{~h}) \approx 314.2 \mathrm{~K}\right)$ and show that the mean increase of potential temperature is $3.5 \mathrm{~K}$ larger in the initially moister CTRL forecast. Thus, the mean increase of potential temperature $\Delta \bar{\theta}$ is $21 \mathrm{~K}$ for the CTRL and $17.5 \mathrm{~K}$ for the EXP_DIAL forecast.

The WCB trajectories in EXP_DIAL start in the region of reduced humidity (Figure 5(a)), which is also apparent in the specific humidity distribution of the WCB trajectories at analysis time (Figure 6(c)). The mean initial humidity is $9.8 \mathrm{~g} \mathrm{~kg}^{-1}$ in the EXP_DIAL analysis and $10.2 \mathrm{~g} \mathrm{~kg}^{-1}$ in the CTRL analysis. During the first $+12 \mathrm{~h}$, humidity decreases only slightly and on average the CTRL WCB trajectories remain moister. Between +12 and $+24 \mathrm{~h}$, the CTRL trajectories lose their moisture more quickly because of faster and stronger proceeding latent-heat processes. The stronger lifting and diabatic heating causes WCB trajectories in the CTRL forecast to reach a higher outflow level and to exhibit lower moisture values. On the other hand, EXP_DIAL 


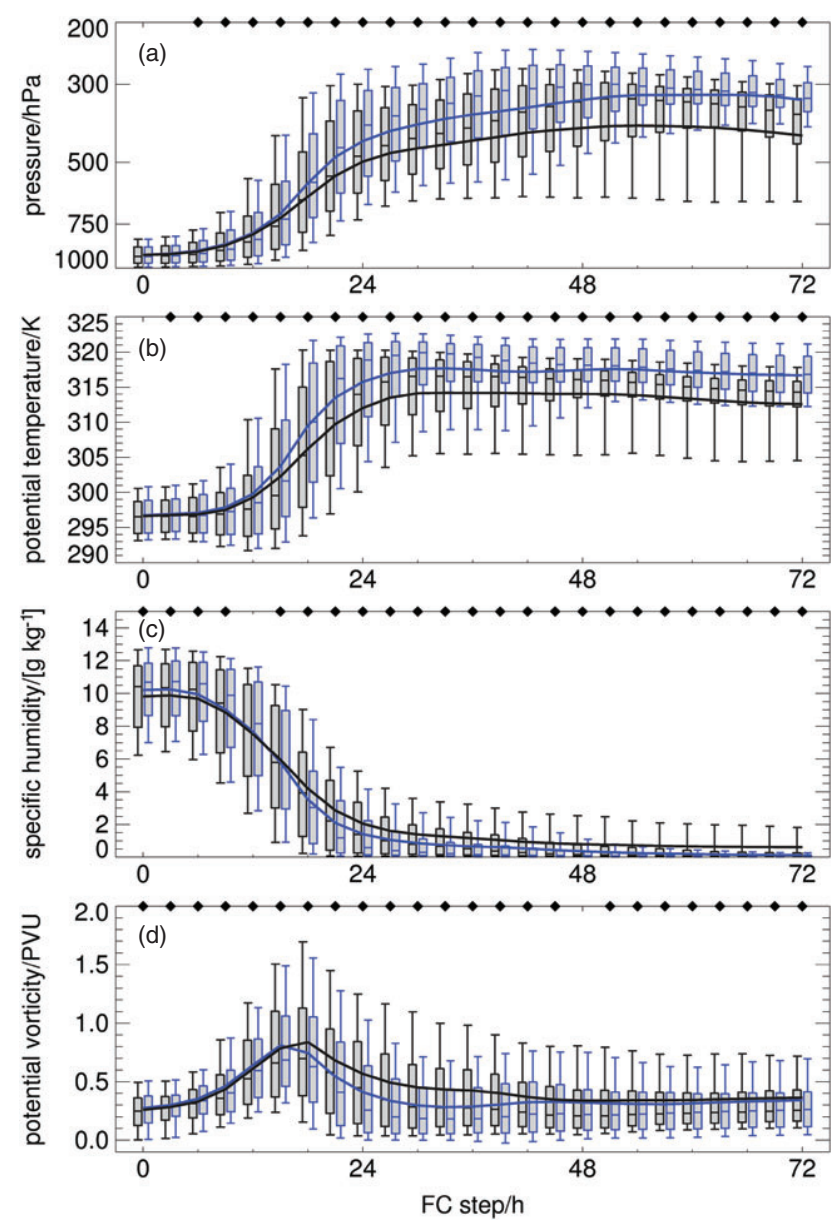

Figure 6. Statistical distribution of (a) pressure, (b) potential temperature, (c) specific humidity and (d) potential vorticity for trajectories identified as warmconveyor-belt trajectories (ascent greater than $500 \mathrm{hPa}$ ) driven by the CTRL (blue) and EXP_DIAL (black) forecast wind fields starting at the same positions at 0000 UTC on 19 September 2008. The box plots in 3-hourly forecast steps indicate the upper and lower quartile and the median of the respective variable. The whiskers indicate the 10th and 90th percentiles. Solid lines show the mean values for the respective 3-hourly forecast time step. Black diamonds on top of each panel indicate statistically significant differences of the mean values at a $99 \%$ confidence level.

WCB parcels remain moister and are located at lower levels in the mid and upper troposphere after $+24 \mathrm{~h}$.

Figure 6(d) shows the evolution of PV. The diabatic generation of PV at lower levels is greatest between +6 and $+15 \mathrm{~h}$, coinciding with an increasing change in potential temperature (see slope of the mean curves in Figure 6(b)). During the first $15 \mathrm{~h}$ the CTRL trajectories produce slightly larger values of PV at lower levels. The EXP_DIAL trajectories generate PV for a longer time, whereas $\mathrm{PV}$ is reduced earlier in the CTRL forecast above the maximum level of latent heating (maximum change in potential temperature is reached at around $700 \mathrm{hPa}$ ). From $+18 \mathrm{~h}$ onwards, more latent heat is released by the initially moister CTRL trajectories and causes a stronger and faster reduction of PV. The higher located CTRL trajectories possess lower PV values in the outflow region, which is located higher due to the more intense release of latent heat.

The small initial differences of geopotential height after $+12 \mathrm{~h}$ (Figure 5(b)) amplify and propagate during the next $24 \mathrm{~h}$. During their ascent, the WCB trajectories are located directly in the region of largest geopotential height differences on the leading edge of the trough. At 1200 UTC on 20 September 2008, after $+36 \mathrm{~h}$ forecast time, the majority of the parcels are lifted above $500 \mathrm{hPa}$ and the release of latent heat decreases (Figure 6(a) and (b)). At this time the cyclone becomes more distinct in the height field (Figure 7(a)). Positive geopotential height differences between EXP_DIAL and CTRL forecast extend over the entire trough region, and values up to $\sim 20 \mathrm{~m}$ can be found at 500
$\mathrm{hPa}$, which implies a weaker cyclone in the EXP_DIAL forecast. The positioning of the cyclone is slightly more progressive in CTRL, with the cyclone centre being located east compared with EXP_DIAL (Figure 7 (a)). The trajectories that remain at $\sim 500 \mathrm{hPa}$ are still coherent and are located to the north of the area of largest geopotential height differences. The majority of WCB parcels at $500 \mathrm{hPa}$ belong to the EXP_DIAL WCB (black dots), which agrees with the higher pressure values of the EXP_DIAL forecast in Figure 6(a). The weaker cyclone in the EXP_DIAL forecast is also visible at $300 \mathrm{hPa}$ (Figure $7(\mathrm{~b})$ ), with geopotential height values being up to $\sim 25 \mathrm{~m}$ larger. Additionally, the downstream ridge features negative differences, which mean that the geopotential is higher for the EXP_DIAL forecast possessing a higher WCB outflow. The relation of the stronger ridging to the stronger WCB is supported by the location of the WCB trajectories.

Figure 8 shows a west-east transect at $56^{\circ} \mathrm{N}$ at a forecast lead time of $+36 \mathrm{~h}$. The cross-section extends from the western part of the ridge at $155^{\circ} \mathrm{E}$ to the eastern side at $190^{\circ} \mathrm{E}$, and intersects the WCB outflow and the area of negative geopotential height differences at $300 \mathrm{hPa}$ (red line in Figure 7(a) and (b)). On the western side of the cross-section, the transition from the upper-level trough to the upper-level ridge can be identified from the increase of the tropopause height (2 PVU isoline) between $160^{\circ} \mathrm{E}$ and $175^{\circ} \mathrm{E}$. Eastwards the tropopause remains at a nearly constant pressure level of $\sim 210 \mathrm{hPa}$ in the region of the ridge, with a small dip found at $180^{\circ} \mathrm{E}$ in the eastern part of the crosssection. In the area from the trough to ridge transition between $160^{\circ} \mathrm{E}$ and $175^{\circ} \mathrm{E}$, the dynamical tropopause (2 PVU contour line) is located $10-20 \mathrm{hPa}(500-1000 \mathrm{~m})$ higher in the CTRL forecast. Strong vertical PV gradients exist at the tropopause, so that the vertical displacement of the tropopause height generates large PV differences at this height interval, with PV values being up to 4 PVU larger in the EXP_DIAL forecasts (Figure $8(a)$ ). Additionally, a distinct vertical layer with moderate positive PVU differences of $0.1-0.5$ PVU can be identified below the tropopause level. They correspond to a less pronounced negative PV anomaly in the EXP_DIAL forecast due to the less intense WCB.

The diabatically active region in the mid troposphere at the leading edge of the trough $\left(160-170^{\circ} \mathrm{E}\right)$ shows large PV differences (Figure 8(a)). The CTRL forecast (Figure 8(c)) possesses higher $\mathrm{PV}$ values at $500 \mathrm{hPa}$ compared with the EXP_DIAL forecast (Figure 8(b)). Furthermore the PV maximum is less homogeneous in EXP_DIAL and shifted slightly to the east. The location of the WCB trajectories at upper levels in an area of low PV values (Figure 8(a)) confirms the importance for the downstream ridge and the location of the tropopause. The fact that the CTRL trajectories (grey dots) are located at higher altitudes suggests that the stronger outflow in the CTRL forecast lifts the tropopause locally. Below the tropopause between $160^{\circ} \mathrm{E}$ and $180^{\circ} \mathrm{E}$ the difference in the $\mathrm{PV}$ values coincides with the WCB outflow. The PV differences at lower levels might be related to the different timing of the ascent of the WCB trajectories in EXP_DIAL and CTRL forecasts, which results in a different structure and intensity of the cyclone forecasts.

To highlight the different WCB outflow strength and its impact on the tropopause, Figure 9 shows the PV distribution at the $322 \mathrm{~K}$ isentropic surface for the CTRL and EXP_DIAL forecasts. Poleward, PV increases as the isentropic surface enters the stratosphere in both forecasts. The trough emerges as a PV streamer, with high PV values propagating southward. The main difference in the PV distribution is found in the downstream ridge, where a broad region of low PV values emerges in the CTRL forecast (blue coloured areas) whereas the EXP_DIAL forecast shows only a small area with PV less than 0.5 PVU. The connection to the WCB outflow is confirmed by the location of the WCB trajectories in the area of low PV at $322 \mathrm{~K}$. The CTRL forecast shows a large amount of parcels, whereas the EXP_DIAL forecast shows only a few at $322 \mathrm{~K}$. The weaker outflow in the EXP_DIAL forecast is associated with a smaller isentropic 

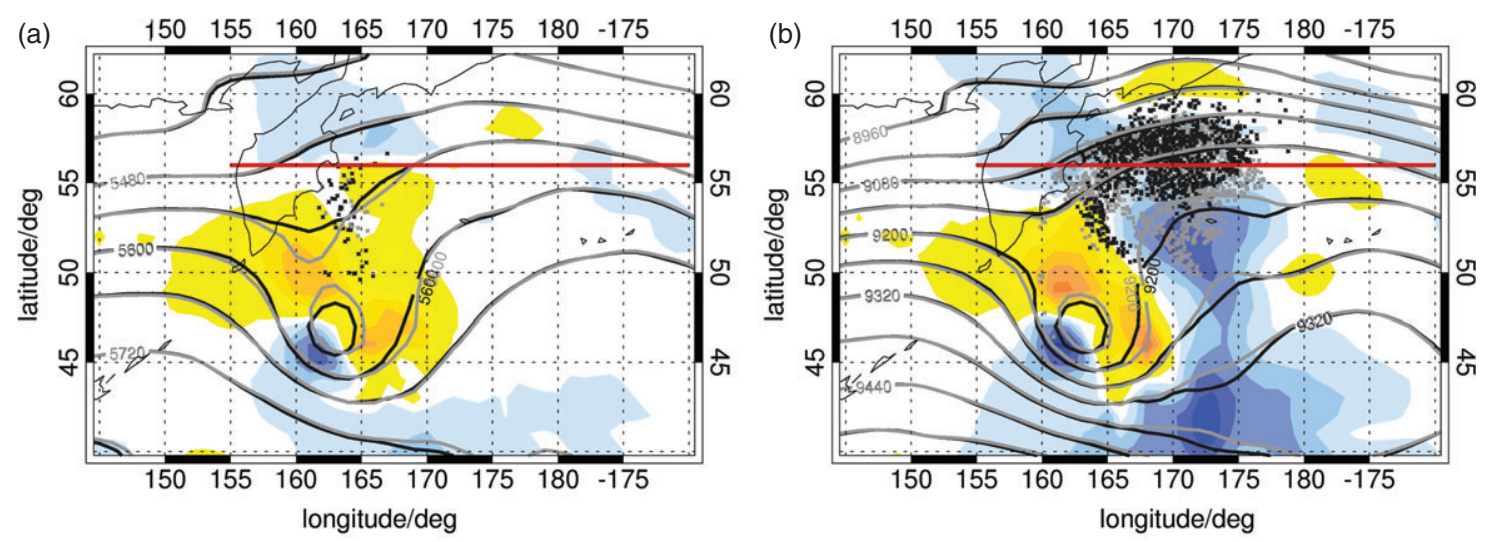

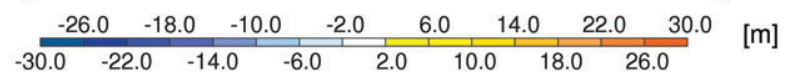

Figure 7. Differences (EXP_DIAL - CTRL) of geopotential height at (a) $500 \mathrm{hPa}$ and (b) $300 \mathrm{hPa}$ at 1200 UTC on 20 September 2008 (+36 h forecast time). Grey (CTRL) and black (EXP_DIAL) contour lines indicate the geopotential height at (a) $500 \mathrm{hPa}$ and (b) $300 \mathrm{hPa}$. Positions of the warm conveyor belt forecast are marked by grey dots for the CTRL and by black dots for the DIAL forecast experiment. All positions at $\pm 10 \mathrm{hPa}$ of the corresponding pressure level are marked. The red line shows the location of the vertical cross-section in Figure 8.
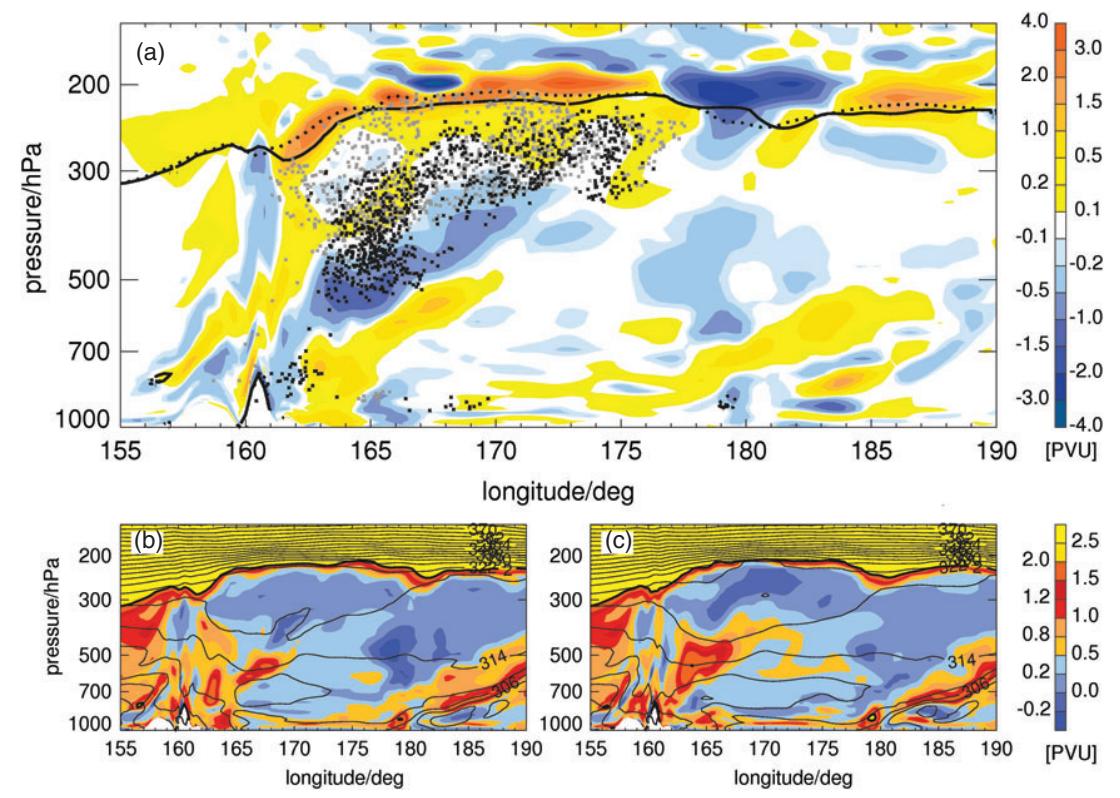

Figure 8. Cross-section at $56^{\circ} \mathrm{N}$ (see red line in Figure 7) at 1200 UTC on 20 September 2008 (+36 h): (a) potential vorticity (PV) differences (EXP_DIAL-CTRL) (colour shaded areas) and 2 PVU isoline of EXP_DIAL (solid line) and CTRL (dashed line) forecasts. The intersection with the warm conveyor belt trajectories are indicated for the CTRL (grey dots) and EXP_DIAL (black dots) forecasts. The PV distribution (colour shaded areas) and potential temperature (black contour lines) forecasts are shown in (b) for EXP_DIAL and in (c) for CTRL.

PV gradient near the tropopause and also with reduced wind speeds in the jet stream at $55-60^{\circ} \mathrm{N}$ (Figure 9). Forecasted wind speeds are smaller by $3-6 \mathrm{~m} \mathrm{~s}^{-1}(5-15 \%)$ in the EXP_DIAL forecast.

After $+48 \mathrm{~h}$, forecast time differences in the geopotential height at $300 \mathrm{hPa}$ further increased in the trough centre $(30 \mathrm{~m}$ higher in the EXP_DIAL forecast), and also in the downstream ridge the negative geopotential-height differences are more strongly pronounced (not shown).

\subsection{Impact on forecast skill}

The change of the low-level humidity in the initial conditions directly affects the forecast of the WCB and the evolution of the upper level trough-ridge pattern. In the following the skill of the different forecasts CTRL and EXP_DIAL is evaluated to see if the changes lead to an improved forecast. Model forecasts of CTRL and EXP_DIAL are verified against the operational ECMWF analysis fields. Harnisch et al. (2011) showed that the forecast error in the EXP_DIAL forecast measured by a total energy norm is reduced by about $6 \%$ after $+48 \mathrm{~h}$ forecast time compared with the CTRL forecast.
Here we want to focus on the effect of the WCB on the forecast error and the forecast impact downstream. A PV forecast impact norm (in PVU) is defined as

$$
\mathrm{I}_{\mathrm{PV}}=\left|\overline{\mathrm{PV}}_{\mathrm{EXP} \_\mathrm{DIAL}}-\overline{\mathrm{PV}}_{\mathrm{AN}}\right|-\left|\overline{\mathrm{PV}}_{\mathrm{CTRL}}-\overline{\mathrm{PV}}_{\mathrm{AN}}\right| .
$$

The PV fields are averaged vertically in a layer between 550 and $900 \mathrm{hPa}$ to illustrate the impact of the different latent heating on the PV structure at low- to mid-tropospheric levels. A kinetic energy (KE) forecast impact norm $\left(\right.$ in $\mathrm{m}^{2} \mathrm{~s}^{-2}$ ) is defined as

$$
\begin{aligned}
I_{\mathrm{KE}}= & {\left[\frac{1}{2}\left(u_{\mathrm{EXP} \_\mathrm{DIAL}}-u_{\mathrm{AN}}\right)^{2}+\frac{1}{2}\left(v_{\mathrm{EXP} \_\mathrm{DIAL}}-v_{\mathrm{AN}}\right)^{2}\right] } \\
& -\left[\frac{1}{2}\left(u_{\mathrm{CTRL}}-u_{\mathrm{AN}}\right)^{2}+\frac{1}{2}\left(v_{\mathrm{CTRL}}-v_{\mathrm{AN}}\right)^{2}\right] .
\end{aligned}
$$

The KE-forecast impact norm is vertically averaged over three levels at 850,500 and $250 \mathrm{hPa}$. Negative values of the PVor KE-forecast impact norm imply a reduction of the forecast error in EXP_DIAL, which corresponds to a beneficial impact of correcting the initial humidity in EXP_DIAL.

Figure 10 displays the PV- and KE-forecast impact norm of EXP_DIAL and CTRL for $+24 \mathrm{~h}$. A PV impact is visible in 

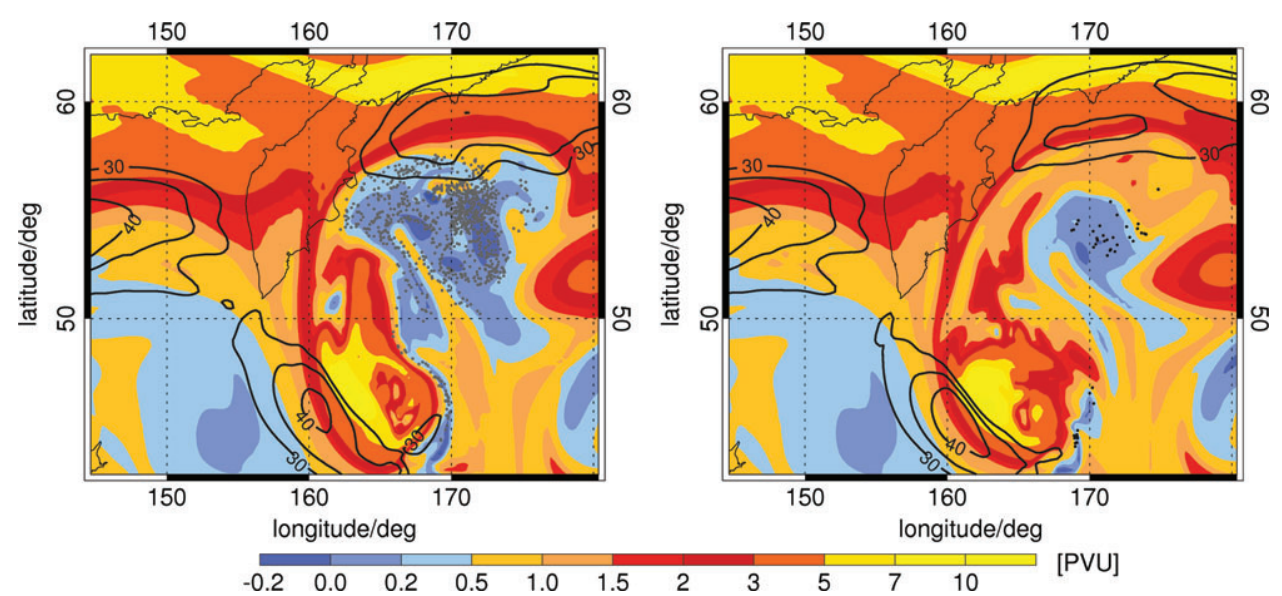

Figure 9. Potential vorticity (PV) (PVU, colour shading) and wind speed ( $\mathrm{m} \mathrm{s}^{-1}$, black contours) on the $322 \mathrm{~K}$ isentropic surface on 20 September 2008 at $1200 \mathrm{UTC}$ $(+36 \mathrm{~h})$ for (a) CTRL and (b) EXP_DIAL. Trajectory positions are marked by grey dots in (a) for the CTRL and by black dots in (b) for the EXP_DIAL forecast. All positions within $\pm 0.5 \mathrm{~K}$ of the isentropic level are marked.

(a) $140145150155160165170175180-175$

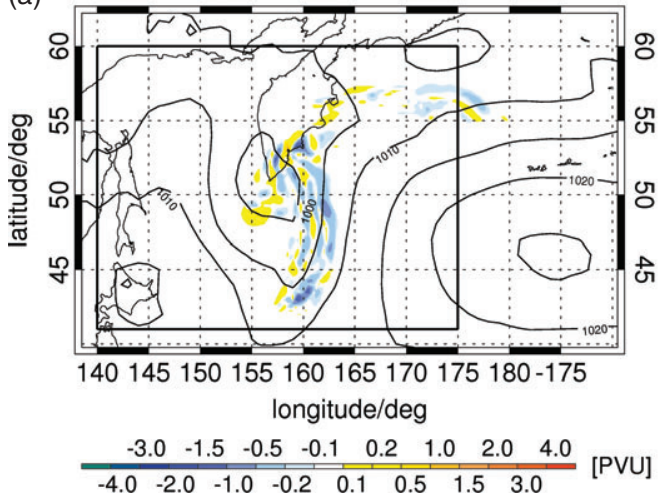

(b) $140145150155160165170175180-175$

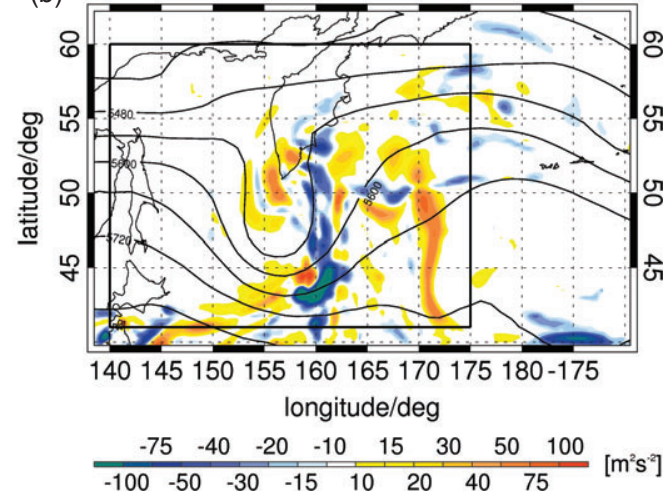

Figure 10. Forecast impact on 20 September $2008(+24 \mathrm{~h})$ in terms of (a) the potential vorticity (PV) norm and (b) the kinetic energy norm. Contour lines show geopotential height of the operational ECMWF analysis at (a) $850 \mathrm{hPa}$ and (b) $500 \mathrm{hPa}$. The black rectangle indicates the domain (140-175 ${ }^{\circ} \mathrm{E}$ and $\left.41-60^{\circ} \mathrm{N}\right)$ used for averaging in Figure 11.

the cyclone centre and north of the surface warm front, with alternating positive and negative values (Figure 10(a)). More pronounced and predominantly negative forecast impact values, which indicate an improvement in EXP_DIAL, are found on the leading edge of the trough east of the surface cold front in the region where the WCB air ascends. Similarly, the KEforecast impact norm (Figure 10(b)) indicates an improvement of the wind fields in the EXP_DIAL forecast on the leading edge of the trough at about the same location where PV is improved.

The relation between the forecast impact of the PV norm and the KE norm is further investigated by analysing the temporal evolution of both norms averaged over the domain shown in Figure 10. The domain was selected to cover the entire trough region over a forecast period of $+48 \mathrm{~h}$, which is the main phase of latent heat release of the WCB. Figure 11 shows spatially averaged values of the forecast impact for the PV and the KE norm. The averaged impact in terms of the PV norm (grey solid line) is neutral during the first $+12 \mathrm{~h}$, in which both forecasts show relatively small differences in the specific humidity and pressure along the WCB trajectories (Figure 6). After $+12 \mathrm{~h}$ the latent heat release begins to increase, which is accompanied by reduced PV errors (negative values) that amplify up to $+30 \mathrm{~h}$. Hence, the reduced moisture in the WCB inflow of the EXP_DIAL experiment results in an improvement of the PV structure at lower levels. The PV impact slightly weakens after $+30 \mathrm{~h}$ and approaches a constant level at $+48 \mathrm{~h}$, when the WCB air mass reaches the WCB outflow and the diabatic processes are completed.

The kinetic energy norm (black solid line) shows an improvement with a time lag of about $12-18 \mathrm{~h}$. Only a small impact is seen for the first $+24 \mathrm{~h}$, but after $+30 \mathrm{~h}$ the impact

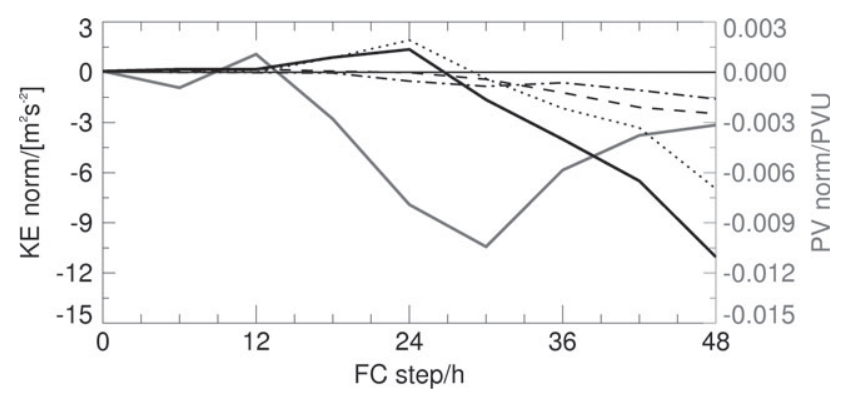

Figure 11. Forecast impact in terms of 550-900 hPa vertically averaged potential vorticity (PV) norm (solid grey line) and kinetic energy (KE) norm (solid black line) consisting of contributions from $250 \mathrm{hPa}$ (dotted), $500 \mathrm{hPa}$ (dashed) and $850 \mathrm{hPa}$ (dash-dotted black line). The impact is averaged in the domain from 140 to $175^{\circ} \mathrm{E}$ and 41 to $60^{\circ} \mathrm{N}$ (see black rectangle in Figure 10).

continuously increases. The break up of the $\mathrm{KE}$ norm into the three different height levels $(250,500,850 \mathrm{hPa})$ illustrates that the improvements start first at the lowest level, with slight improvements of the $850 \mathrm{hPa}$ wind fields at $+24 \mathrm{~h}$ forecast time. The improvement propagates vertically and subsequently emerges at 500 and $250 \mathrm{hPa}$ at $+30 \mathrm{~h}$ forecast time. The small deterioration of the averaged $\mathrm{KE}$ norm at $+24 \mathrm{~h}$ forecast time mainly results from the contribution at $250 \mathrm{hPa}$ wind fields in the downstream ridge region (Figure 10(b)).

The humidity change also had an impact on the MinSLP (not shown). At $+24 \mathrm{~h}$ a more intense surface cyclone develops in the CTRL forecast $(994.9 \mathrm{hPa})$ compared with the EXP_DIAL forecast $(996.43 \mathrm{hPa})$. The higher MinSLP in the EXP_DIAL forecast agrees better with the analysis $(996.4 \mathrm{hPa})$. 

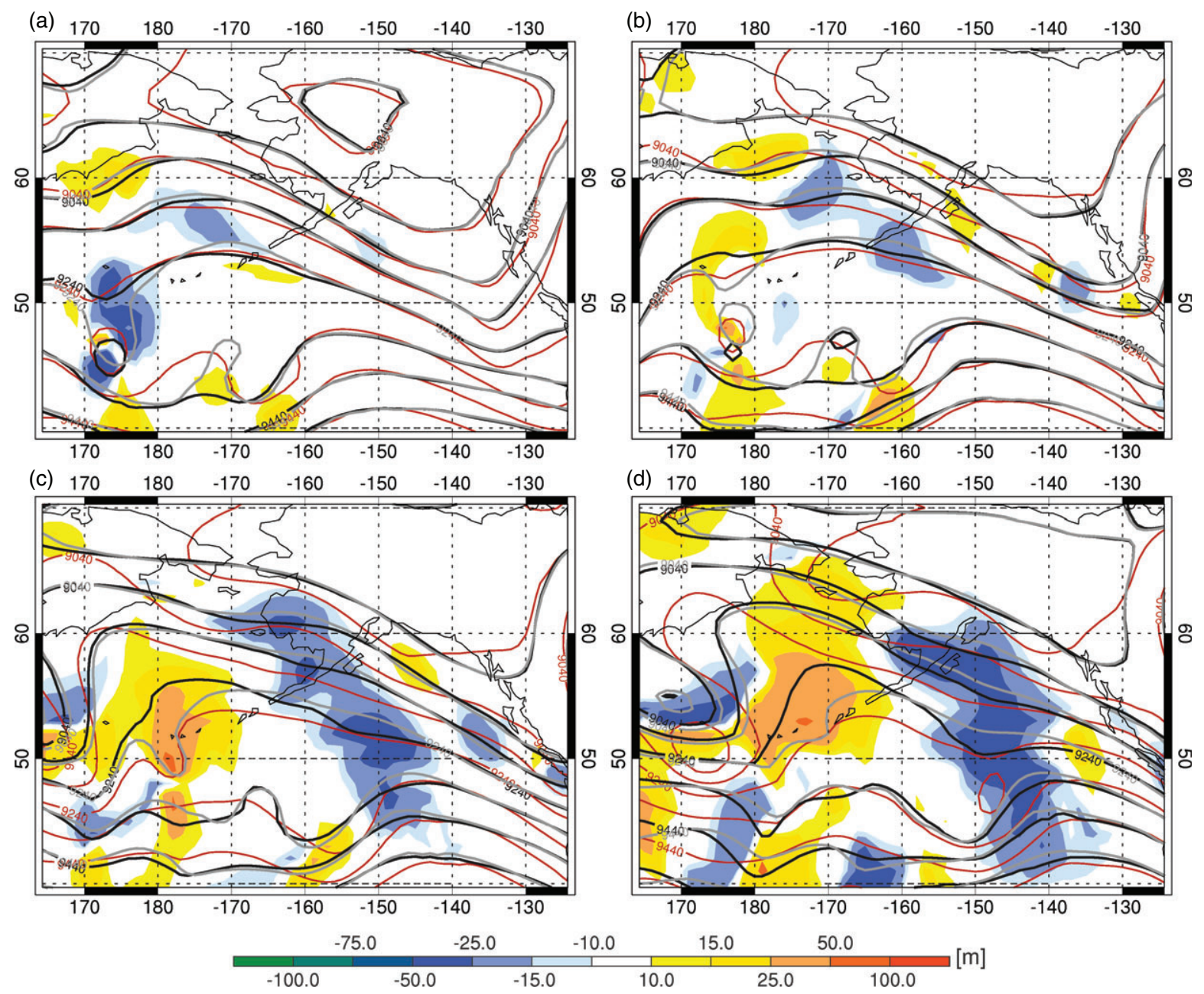

Figure 12. Forecast error difference of EXP_DIAL - CTLR for geopotential height (colour shaded areas) at $300 \mathrm{hPa}$ for $(\mathrm{a})+60 \mathrm{~h},(\mathrm{~b})+72 \mathrm{~h},(\mathrm{c})+84 \mathrm{~h}$ and (d) $+96 \mathrm{~h}$ forecast time. Geopotential height contours of operational analysis (red), EXP_DIAL (black contour lines) and CTRL (grey) forecast.

Figure 12 shows the impact in terms of the geopotential height at $300 \mathrm{hPa}$ from +60 to $+96 \mathrm{~h}$. After $+60 \mathrm{~h}$ the forecast of the cyclone is still improved and the EXP_DIAL experiment reveals a lower geopotential height error near the centre of the upper-level cyclone (Figure 12(a)). The EXP_DIAL forecast produces a less intense and slightly shifted cyclone, which contributes to the reduction of the forecast error. Additionally, an improvement of the geopotential height forecast is found in the outflow area of the WCB, which spreads downstream over the Atlantic (ridge axis at about $175^{\circ} \mathrm{W}$ ) from +72 to $+96 \mathrm{~h}$ (Figure $12(\mathrm{~b})-(\mathrm{d})$ ). Even though the representation of the new upstream system is degraded in the EXP_DIAL forecast, the improvements with the WCB are still apparent and have propagated downstream.

\section{Summary and conclusions}

During a T-PARC aircraft mission over the western North Pacific on 19 September 2008, an airborne DIAL instrument collected a set of high-resolution, accurate, water vapour measurements. By applying a Lagrangian trajectory diagnostic, it was demonstrated that parts of the DIAL observations are covering a moist layer close to the sea surface that represents the inflow region of a developing WCB. The observed air mass is embedded into a WCB shortly after the observation time. Maximum ascent rates of $650 \mathrm{hPa}$ in $+48 \mathrm{~h}$ are diagnosed for the WCB trajectories.

By assimilating the DIAL observations in the ECMWF 4DVar data assimilation system, an analysis with a modified representation of the moisture content in the WCB inflow is produced. A reduction of the humidity in the model analysis appears in a broad region around the flight track and leads to an improved agreement between model fields and observations, as shown by comparison with independent dropsonde measurements (Harnisch et al., 2011). The area of reduced humidity coincides with the WCB inflow region, which implies that a different amount of moisture is available to become transported into the WCB.

The impact of the modified initial humidity on the forecast of the WCB is examined by comparing two ECMWF forecast experiments, which are initialized from the modified analysis that includes the DIAL water vapour data and a control analysis, respectively. The comparison of the different forecasts reveals that the reduction of humidity in the initial conditions is accompanied by a reduction of the latent heat release by $3.5 \mathrm{~K}$ along the ascending WCB trajectories. Less PV is produced at lower levels and, additionally, the mean trajectory height in the WCB outflow is $\sim 70 \mathrm{hPa}$ lower. In the forecast with reduced humidity, a weaker cyclone develops and the weaker WCB outflow causes a lower local tropopause (by up to $20 \mathrm{hPa}$ ). The comparison of PV on isentropic surfaces shows a reduced isentropic PV gradient and lower jet stream wind speeds $(5-15 \%)$ in the downstream ridge for the forecasts based on the analysis with the DIAL data.

The forecasts have been verified against operational ECMWF analyses to evaluate the impact on the forecast skill. The reduction of humidity improves the PV structure in the lower and mid troposphere, especially during the period of strong latent heat release in the ascending phase of the WCB evolution. An improvement of the wind fields of the cyclone is indicated by a reduced KE forecast error. The impact on the KE emerges with a temporal shift of $12-18 \mathrm{~h}$ after the PV impact, whereby at first the lower-level wind fields show an improvement that propagates vertically to the upper troposphere. Furthermore, the 
MinSLP is better represented in the EXP_DIAL forecast, which has improved initial conditions. The cyclone does not further intensify after $+48 \mathrm{~h}$ and separates from the background flow before decaying after about $+72 \mathrm{~h}$, so that no considerable impact could be identified on the medium-range forecast. However, the modified WCB outflow leads to a reduced forecast error of the geopotential height in the downstream ridge, which persists up to $+96 \mathrm{~h}$ and propagates downstream over the Pacific Ocean.

This case study demonstrated the importance of diabatic processes in a WCB for an extratropical cyclogenesis and evolution of the upper-level circulation. Initially, by assimilating the DIAL humidity data, the low-level humidity in the inflow region of a WCB was reduced. These small deviations (maximum values of $2 \mathrm{~g} \mathrm{~kg}^{-1}$ ) of the available moisture content were able to considerably affect the evolution of the connected extratropical cyclone and the downstream ridge. The reduced wind speed of the jet stream and the weaker ridge building downstream agree with other studies that investigated the role of diabatic processes on the upper-level wave guide by applying the PV inversion technique that removes the entire cyclone in the initial model fields (e.g. Grams et al., 2011). However, the approach presented represents a realistic modification of the initial conditions in the inflow of the WCB, whereas the PV inversion technique could be considered as a maximum impact scenario. Grams et al. (2011) showed that the removal of the cyclone led to a reduced wind speed of the jet stream of $25 \%$, which is larger compared with the $5-15 \%$ reduction found in this study. Also the downstream impact shown here is less pronounced compared with Massacand et al. (2001) and Grams et al. (2011), which could be due to the early formation of a cut-off low and the associated separation from the background flow in our case. However, WCBs occur frequently in the midlatitudes (Eckhardt et al., 2004) and one could think of stronger developed and longer lasting WCBs with a comparable humidity error as found here may have a greater impact on the medium-range forecast.

The comparison of lidar observations in other regions has shown that misrepresentation of low-level humidity is often present in NWP models (Schäfler et al., 2010, 2011). The humidity errors presumably result from errors in the surface fluxes and large-scale transport (Schäfler et al., 2011) or from analysis errors due to lacking humidity observations in the lower troposphere. We have demonstrated in this case study, which is an outcome of a lucky WCB encounter with airborne DIAL measurements, that NWP analysis humidity errors reach a magnitude that can have a considerable effect on the dynamics. It should be noted that, for this case, the assimilation of the DIAL humidity profiles showed the greatest forecast impact of all flights during T-PARC (Harnisch et al., 2011). This high impact highlights that WCBs are an important mechanism that enables humidity errors to interact with the larger scale dynamics and to influence the medium range predictability.

Another potential source of NWP model forecast error during a WCB ascent results from the misrepresentation of parametrized cloud processes. The question of how good diabatic heating inside a WCB is represented in NWP systems was the focus of a recent airborne research campaign named T-NAWDEXFalcon, which was investigated by performing Lagrangian flights at different stages of the WCB (Schäfler et al., 2013). Other factors influenced by various diabatic processes, such as convection, TCs undergoing extratropical transition and tropopause polar vortices are also believed to affect the midlatitude waveguide. It is the aim of a prospective internationally coordinated THORPEX North Atlantic Waveguide and Downstream Impact Experiment (T-NAWDEX) in 2016 to investigate factors causing systematic errors in the model representation of waveguide perturbations, to quantify the magnitude of errors in the waveguide and to study their transport and downstream impact by independent measurements on a transatlantic scale with the new German research aircraft HALO.

\section{Acknowledgements}

The authors are grateful for the efforts of the pilots and system operators. Especially, we thank Drs Christoph Kiemle and Martin Wirth (both DLR) for processing the lidar data. The authors thank the European Centre for Medium-range Weather Forecasts (ECMWF) for providing data and computer resources in the framework of the special project 'Support Tool for HALO missions'. The support of various people at ECMWF for the assimilation experiments and ECMWF computing resources are greatly appreciated. The German Research Foundation (DFG) funded the work of AS within the Priority Program SPP 1167 QPF (Quantitative Precipitation Forecast). F. Harnisch is part of the Hans-Ertel-Centre for Weather Research, a network of universities, research institutes and Deutscher Wetterdienst funded by the German Federal Ministry of Transport and Digital Infrastructure. The authors thank Dr Oliver Reitebuch for his valuable comments on the manuscript. The authors thank Professor Martin A. Baxter and an anonymous reviewer for their constructive and useful comments, which significantly helped to improve this manuscript.

\section{References}

Bauer P, Geer AJ, Lopez P, Salmond D. 2010. Direct 4D-Var assimilation of all-sky radiances. Part I: Implementation. Q. J. R. Meteorol. Soc. 136: 1868-1885.

Bhawar R, Di Girolamo P, Summa D, Flamant C, Althausen D, Behrendt A, Kiemle C, Bosser P, Cacciani M, Champollion C, Di Iorio T, Engelmann R, Herold C, Pal S, Wirth M, Wulfmeyer V. 2011. The water vapour intercomparison effort in the framework of the Convective and Orographically-induced Precipitation Study: Airborne-to-ground-based and airborne-to-airborne lidar systems. Q. J. R. Meteorol. Soc. 137 325-348.

Browning KA, Hardman ME, Harrold TW, Pardoe CW. 1973. Structure of rainbands within a mid-latitude depression. Q. J. R. Meteorol. Soc. 99: $215-231$.

Carlson TN. 1980. Airflow through midlatitude cyclones and the comma cloud pattern. Mon. Weather Rev. 108: 1498-1509.

Davis CA, Stoelinga MT, Kuo YH. 1993. The integrated effect of condensation in numerical simulations of extratropical cyclogenesis. Mon. Weather Rev. 121: 2309-2330.

Eckhardt S, Stohl A, Wernli H, James P, Forster C, Spichtinger N. 2004. A 15-year climatology of warm conveyor belts. J. Clim. 17: 218-237.

Grams CM, Wernli H, Boettcher M, Campa J, Corsmeier U, Jones SC, Keller JH, Lenz CJ, Wiegand L. 2011. The key role of diabatic processes in modifying the upper tropospheric wave guide: A North Atlantic case-study. Q. J. R. Meteorol. Soc. 137: 2174-2193.

Harnisch F, Weissmann M. 2010. Sensitivity of typhoon forecasts to different subsets of targeted dropsonde observations. Mon. Weather Rev. 138: 2664-2680.

Harnisch F, Weissmann M, Cardinali C, Wirth M. 2011. Experimental assimilation of DIAL water vapour observations in the ECMWF global model. Q. J. R. Meteorol. Soc. 137: 1532-1546.

Hastings D, Dunbar P, Elphingstone G, Bootz M, Murakami H, Maruyama H, Masaharu H, Holland P, Payne J, Bryant N, Logan TL, Muller J-P, Schreier G, MacDonald JS. 1999. The Global Land One-kilometer Base Elevation (GLOBE) Digital Elevation Model. Version 1.0. National Oceanic and Atmospheric Administration. National Geophysical Data Center: Boulder, CO.

Kiemle C, Brewer W, Ehret G, Hardesty R, Fix A, Senff C, Wirth M, Poberaj G, LeMone M. 2007. Latent heat flux profiles from collocated airborne water vapour and wind lidars during IHOP 2002. J. Atmos. Oceanic Technol. 24: 627-639.

Kiemle C, Wirth M, Fix A, Ehret G, Schumann U, Gardiner T, Schiller C, Sitnikov N, Stiller G. 2008. First airborne water vapor lidar measurements in the tropical upper troposphere and mid-latitudes lower stratosphere: Accuracy evaluation and intercomparisons with other instruments. Atmos. Chem. Phys. 8: 10353-10396.

Knippertz P, Martin JE. 2005. Tropical plumes and extreme precipitation in subtropical and tropical West Africa. Q. J. R. Meteorol. Soc. 131: 2337-2365.

Kuo YH, Shapiro MA, Donall EG. 1991. The interaction between baroclinic and diabatic processes in a numerical simulation of a rapidly intensifying extratropical marine cyclone. Mon. Weather Rev. 119: 368-384.

Massacand AC, Wernli H, Davies HC. 2001. Influence of upstream diabatic heating upon an alpine event of heavy precipitation. Mon. Weather Rev. 129: $2822-2828$.

Pomroy HR, Thorpe AJ. 2000. The evolution and dynamical role of reduced upper-tropospheric potential vorticity in intensive observing period one of FASTEX. Mon. Weather Rev. 128: 1817-1834. 
Rabier F, Jarvinen H, Klinker E, Mahfouf JF, Simmons A. 2000. The ECMWF operational implementation of four-dimensional variational assimilation. I: Experimental results with simplified physics. Q. J. R. Meteorol. Soc. 126: 1143-1170.

Rossa AM, Wernli H, Davies HC. 2000. Growth and decay of an extratropical cyclone's PV-tower. Meteorol. Atmos. Phys. 73: 139-156.

Schäfler A, Dörnbrack A, Kiemle C, Rahm S, Wirth M. 2010. Tropospheric water vapour transport as determined from airborne lidar measurements. J. Atmos. Oceanic Technol. 27: 2017-2030.

Schäfler A, Dörnbrack A, Wernli H, Kiemle C, Rahm S. 2011. Airborne lidar observations in the inflow region of a warm conveyor belt. Q. J. R. Meteorol. Soc. 137: 1257-1272.

Schäfler A, Boettcher M, Dörnbrack A, Grams CM, Hausold A, Rautenhaus M, Reutter P, Schlager H, Sodemann H, Voigt C, Wernli H. 2014. Planning of aircraft measurements within a warm conveyor belt. Weather, doi: 10.1002/wea.2245.

Weissmann M, Langland RH, Cardinali C, Rahm S. 2012. Influence of airborne Doppler wind lidar profiles near Typhoon Sinlaku on ECMWF and NOGAPS forecasts. Q. J. R. Meteorol. Soc. 138: 118-130.

Wernli H. 1997. A lagrangian-based analysis of extratropical cyclones. II. A detailed case-study. Q. J. R. Meteorol. Soc. 123: 467-489.

Wernli H, Davies HC. 1997. A lagrangian-based analysis of extratropical cyclones. I. The method and some applications. Q. J. R. Meteorol. Soc. 123 1677-1706.

Wirth M, Fix A, Mahnke P, Schwarzer H, Schrandt F, Ehret G. 2009. The airborne multi-wavelength water vapour differential absorption lidar WALES: System design and performance. Appl. Phys. B 63: $201-213$ 